\title{
Design of Polymer-Coated Multi-Walled Carbon Nanotube/Carbon Black-based Fuel Cell Catalysts with High Durability and Performance Under Non-humidified Condition
}

\author{
Zehui Yang, ${ }^{a}$ Mohamed R. Berber ${ }^{\text {b,c }}$ and Naotoshi Nakashima ${ }^{\text {aa,b,d }}$ \\ ${ }^{a}$ Department of Applied Chemistry, Graduate School of Engineering, Kyushu University, 744 \\ Motooka, Nishi-ku, Fukuoka 819-0395, Japan \\ ${ }^{b}$ International Institute for Carbon Neutral Energy Research (WPI-I2CNER), Kyushu \\ University, Fukuoka 819-0395, Japan \\ ${ }^{c}$ Department of Chemistry, Faculty of Science, Tanta University, Tanta 31527, Egypt \\ ${ }^{d}$ JST-CREST, 5 Sanbancho, Chiyoda-ku, Tokyo, 102-0075, Japan
}

To whom correspondence should be addressed:

E-mail: nakashima-tcm@mail.cstm.kyushu-u.ac.jp 


\section{Abstract}

To realize a high catalyst utilization, better fuel cell performance and durability as well as low production cost, an efficient design strategy of the catalyst layer that can improve both the oxygen accessibility and structure stability is highly required. Here, we describe the preparation of fuel cell electrocatalysts with an efficient fuel cell performance and better stability based on hybrids of multi-walled carbon nanotubes (MWNTs) and carbon black (CB) which were wrapped by a proton conducting polymer, poly[2,2'-(2,6-pyridine)-5,5'-bibenzimidazole], before deposition of the platinum (Pt) metal catalyst. The catalyst mass activity after feeding only $10 \%$-MWNTs to CB increased by 1.5 and 2 times than those of the MWNTs-based- and CB-based catalysts, respectively. The results also demonstrated that $90 \mathrm{wt} \%$ of the MWNTs in the catalyst layer allows it to be replaced by $\mathrm{CB}$ without any significant change in its durability and performance under $120{ }^{\circ} \mathrm{C}$ and non-humidified condition.

Keywords: Carbon black, Carbon nanotubes, Catalyst, Durability, Fuel cell, Non-humidified condition. 


\section{Introduction}

Fuel cells, in particular polymer electrolyte membrane fuel cells (PEMFCs), are receiving increasing attention for transportation, portable electronic devices and power supplies due to their high energy density, high efficiency and green emissions. [1-9] It has been widely recognized that cost, performance and durability are the main roadblocks that prevent PEMFCs from reaching their wide spread applications. [10]

The PEMFC electrocatalysts strongly affect the final production cost of the FC units.[11] In addition, they mainly determines the lifetime of the PEMFC unit. [12] These electrocatalysts are usually based on metal-supported carbon materials. Platinum (Pt) as a precious metal has been widely used as a catalyst for both the anode and the cathode of the membrane electrode assemblies (MEAs) due to its high durability and catalytic activity compared to the other metals or metal oxide catalysts. [13-19] The mass activity of Pt strongly depends on the carbon supports, [20] and several kinds of carbon materials have been introduced as catalyst supports in order to increase the Pt electrochemical surface areas. Carbon black (CB) has been the most widely used carbon support in the PEMFCs because it is commercially available, has a high surface area, high electrical conductivity and low cost compared to the other carbon support materials. However, it undergoes a fast corrosion process in terms of durability during the FC operation process, especially under high temperature operating conditions. [21] Therefore, the use of $\mathrm{CB}$ accelerates the degradation process of the corresponding MEA, leading to a short life time of the FC. Hence, searching for a new technique that improves the 
durability of the FC catalyst-support, while reducing its cost, has become an essential and urgent target for the global commercialization of the FCs.

The graphitization of CB to change its morphology or to modify its nanostructures through the enhancement of its crystal degree was one of the techniques of improving the durability of $\mathrm{CB}$, while graphitization usually results in lowering the interaction between the $\mathrm{CB}$ and $\mathrm{Pt}$ nanoparticles (NPs), leading to aggregation of the Pt-NPs and the loss of the active surface area. $[22,23]$ Recently, Gharibi et al. reported that feeding MWNTs into a micro-porous catalyst layer containing CB enhanced the oxygen reduction reaction (ORR). [24] Kim et al. sputtered Pt on the MWNTs-CB hybrid supports and got the highest electrochemical surface area (ECSA, $20.6 \mathrm{~m}^{2} / \mathrm{g}_{\mathrm{Pt}}$ ) with the weight ratio of 50:50. [25] Chua et al. also directly sputtered Pt on CNT grown on carbon paper and found an enhancement in power density compared to CB-based gas diffusion electrode (GDE). [26] Meanwhile, Ramaprobhu et al. and Yan et al. loaded the Pt-NPs on the hybrids of acid-oxidized MWNTs and CB and reported the optimized weight ratio (50:50) according to the FC performance. [27, 28] However, in these studies, the durability of the electrocatalysts was not clear. Moreover, the lack of triple phase boundary (TPB) resulted in the low Pt utilization, and the oxidization of the MWNTs lowered the long-term durability of the electrocatalyst. Thus, the development of an electrocatalyst using the pristine MWNTs-CB as the carbon support having a high $\mathrm{Pt}$ utilization efficiency and long-term durability is strongly required. Especially, such 
performance is important in the design and development of high-temperature PEMFC having advantages of higher carbon monoxide (CO) tolerance, faster electrochemical kinetics, and easier water management. [29, 30]

Recently, we reported a homogeneous deposition technique of Pt nanoparticles onto the surfaces of the pristine-MWNTs, in which the MWNTs were first wrapped with a proton conducting polymer, poly[2,2'-(2,6-pyridine)-5,5'-bibenzimidazole] (PyPBI), before immobilization of the Pt-NPs. The PyPBI-wrapped MWNT composite worked as a binding site for the Pt-NPs. The obtained electrocatalyst exhibited a high Pt utilization efficiency, a high fuel cell performance and a remarkable durability as well as the fabrication of TPB due to the presented unique technique of Pt immobilization and the remarkable mechanical and electrical properties of the MWNTs that make the feeding of the reactant and the transfer of the electrons from/to the active sites in the catalyst layer more facile. [31-34] Thus, we applied the polymer wrapping method to the pristine MWNTs-CB hybrid supporting materials to improve the Pt utilization and long-term durability in the non-humidified high-temperature PEMFC.

Herein, in this study, we prepared FC electrocatalysts with hybrid support materials by varying the blending ratios of the $\mathrm{CB}$ and MWNTs that were wrapped by PyPBI. The electrochemical surface area (ECSA) durability and oxygen reduction reaction (ORR) as well as the high temperature fuel cell performance of the obtained electrocatalysts under 
non-humidified conditions were investigated in detail. We here describe the first report on the use of MWNTs-CB hybrid supporting materials in non-humidified high temperature PEMFC studies.

\section{Experimental}

\subsection{Materials}

LiBr was supplied by Nacalai Tesque, Ltd. 2-Propanol, $N, N$-dimethylacetamide (DMAc), ethylene glycol (EG), hydrogen hexachloroplatinate hexahydrate $\left(\mathrm{H}_{2} \mathrm{PtCl}_{6} \cdot 6 \mathrm{H}_{2} \mathrm{O}\right)$, and $85 \%$ phosphoric acid (PA) were purchased from Wako Pure Chemical, Ltd. The MWNTs with 20-nm diameter were kindly provided by the Nikkiso Corp. CB (Vulcan XC-72R) was purchased from the Cabot Chemical Co. CB/Pt was purchased from Tanaka Kikinzoku Kogyo K. K., in which 37.9 wt\% of Pt-NPs was supported on Vulcan ${ }^{\circledR}$ XC-72. All the chemicals were used as received without any purification. PyPBI and poly[2,2'-(2,6-phenyl)-5,5'-bibenzimidazole] (PBI) were synthesized according to previously reported methods. $[35,36]$

\subsection{Synthesis of the electrocatalysts}

In a flask, $\mathrm{x}$ mg of the MWNTs and $\mathrm{y}$ mg of $\mathrm{CB}(\mathrm{x}+\mathrm{y}=10 \mathrm{mg})$ were placed in DMAc (20 $\mathrm{mL}$ ) and dispersed by sonication (Yamato 5510, Branson) for $1 \mathrm{~h}$ to obtain a CB-MWNT mixture, to which PyPBI dissolved in $10 \mathrm{~mL}$ of DMAc was mixed and sonicated for $2 \mathrm{~h}$. The

formed composite was filtered, and then dried overnight under vacuum at $80{ }^{\circ} \mathrm{C}$. The 
deposition of the Pt-NPs was carried out by the reduction of $\mathrm{H}_{2} \mathrm{PtCl}_{6} \cdot 6 \mathrm{H}_{2} \mathrm{O}$ in an $\mathrm{EG}$ aqueous solution at $140{ }^{\circ} \mathrm{C}$. First, $10 \mathrm{mg}$ of the PyPBI/MWNTs/CB composite was dispersed in a 30 mL EG aqueous solution to which aqueous EG $(20 \mathrm{~mL})$ containing $24 \mathrm{mg}$ of $\mathrm{H}_{2} \mathrm{PtCl}_{6} \cdot 6 \mathrm{H}_{2} \mathrm{O}$ was added, then refluxed at $140{ }^{\circ} \mathrm{C}$ for $6 \mathrm{~h}$ under a $\mathrm{N}_{2}$ atmosphere. The obtained composite was collected by filtration, and then dried overnight at $60{ }^{\circ} \mathrm{C}$. The composites with various ratios of the MWNTs and $\mathrm{CB}$ were denoted as $\mathrm{PyPBI} /{ }_{\mathrm{x}} \mathrm{MWNT}-{ }_{\mathrm{y}} \mathrm{CB} / \mathrm{Pt}$, where the ${ }_{\mathrm{x}}$ and $\mathrm{y}_{\mathrm{y}}$ values are the feeding ratios of the MWNTs and $\mathrm{CB}$, respectively.

\subsection{Material characterization}

The X-ray photoelectron spectra (XPS) were measured using an AXIS-ULTRA ${ }^{\text {DLD }}$ (Shimadzu). Thermal gravimetric analysis (TGA) measurements were conducted with an EXSTAR 6000 (Seiko, Inc.) at the heating rate of $5^{\circ} \mathrm{C} / \mathrm{min}$ under $100 \mathrm{~mL} / \mathrm{min}$ flowing air. The transmittance electron micrographs (TEM) were obtained using a JEM-2010 (JEOL) electron microscope at the acceleration voltage of $120 \mathrm{kV}$. A copper grid with a carbon support (Okenshoji) was used for the TEM observations. X-ray diffraction (XRD) measurements were carried out by using a Rigaku SmartLab diffractometer $(\mathrm{Cu}, \mathrm{K} \alpha$, $\lambda=1.5406 \AA, 40 \mathrm{kV}$, and $30 \mathrm{~mA}$ ), the diffraction patterns were collected from $20^{\circ}$ to $90^{\circ}$ at a scan rate of $1 \%$ min and with a step of $0.01^{\circ}$.

\subsection{Electrochemical and durability measurements}

The electrochemical measurements were performed on a rotating ring disk electrode 
connected to a rotating ring disk instrument, RRDE-3 (Bioanalytical Systems, Inc.) with a conventional three-electrode configuration in a vessel at room temperature. A glassy carbon electrode (GCE) with a geometric surface area of $0.196 \mathrm{~cm}^{2}$ was used as the working electrode. A Pt wire and an $\mathrm{Ag} / \mathrm{AgCl}$ were used as the counter and reference electrodes, respectively. The potential of the electrode was controlled by an ALS-Model DY2323 (BAS) potentiostat. Typically, the catalyst suspension was prepared as follows. The composite (1.0 $\mathrm{mg}$ ) was ultrasonically dispersed in an $80 \%$ aqueous EG solution $(2.0 \mathrm{~mL})$, and a portion of the dispersion was then cast on a GCE to provide a catalyst layer (the loading amount of $\mathrm{Pt}$ was controlled at $14 \mu \mathrm{g} / \mathrm{cm}^{2}$ ). Finally, the cast film on the electrode was air-dried. The cyclic voltammetry $(\mathrm{CV})$ measurements of the electrocatalysts at the scan rate of $50 \mathrm{mV} / \mathrm{s}$ were carried in an $\mathrm{N}_{2}$-saturated $0.1 \mathrm{M} \mathrm{HClO}_{4}$ solution in order to determine the electrochemical surface areas (ECSAs). The measurements were repeated twice to determine the average of the ECSA values. The oxygen reaction reduction (ORR) was tested in an $\mathrm{O}_{2}$-saturated $0.1 \mathrm{M}$ $\mathrm{HClO}_{4}$ solution at room temperature at the scan rate of $10 \mathrm{mV} / \mathrm{s}$. Durability test was carried out by continued $\mathrm{CV}$ cycling from -0.17 to $0.93 \mathrm{~V}$ vs. $\mathrm{Ag} / \mathrm{AgCl}$. The ECSA values were calculated after every $200 \mathrm{CV}$ cycles, and the results were used to obtain the normalized ECSA values.

\subsection{Fuel cell test}

Typical fabrication procedure of a gas diffusion electrode (GDE) is as follows. The 
composite was dispersed in a $50 \mathrm{~mL}$ 2-propanol aqueous solution by sonication for $1 \mathrm{~h}$. The obtained solution was filtered using a gas diffusion layer (GDL) as the filter paper. The Pt loading amount on the GDL was controlled at $0.45 \mathrm{mg} / \mathrm{cm}^{2}$. The obtained GDE was dried overnight under vacuum at room temperature to remove any residual solvent.

In a 50-mL glass bottle, $100 \mathrm{mg}$ of $\mathrm{LiBr}$ was dissolved in $10 \mathrm{~mL}$ of DMAc, to which $200 \mathrm{mg}$ of PBI polymer was added. The bottle was then sealed under $\mathrm{N}_{2}$ and magnetically stirred at $50{ }^{\circ} \mathrm{C}$ for 1 day to dissolve the polymer. The DMAc was then evaporated to obtain a solution with a PBI content of around $4 \mathrm{wt} \%$. The resultant PBI polymer solution was carefully cast on a glass plate using a film applicator (Elcometer 3600, 50mm strip width). The DMAc was then gradually evaporated from the cast solution till the temperature reached $120{ }^{\circ} \mathrm{C}$. The heating process was further continued at $120^{\circ} \mathrm{C}$ for another $5 \mathrm{~h}$ to completely remove the solvent. The PBI film was peeled off the glass substrate and immersed several times in hot Milli-Q water (each $\sim 30 \mathrm{~min}$ ) in order to remove LiBr. Finally, the PBI membrane was placed in a $85 \mathrm{wt} \%$ PA solution for 5 days to dope PA to the film. The obtained membrane thickness was determined to be $\sim 25 \mu \mathrm{m}$. The amount of PA loaded in the membrane was calculated by the weight change from the dry membrane upon doping. The doping level was 5 PA molecules/repeat unit of PBI.

Membrane electrode assemblies (MEAs) were prepared by hot pressing the GDE and the PBI membrane under $2 \mathrm{MPa}$ at $120^{\circ} \mathrm{C}$ for $30 \mathrm{~s}$. The MEA active area was $1 \mathrm{~cm}^{2}$. The FC 
performance of the assembled MEA was evaluated at $120{ }^{\circ} \mathrm{C}$ without any external humidification using a computer-controlled fuel cell test system (Model 890e, Scribner Associate, Inc.). The polarization and the power density curves were obtained under atmospheric pressure in flowing dry hydrogen (flow rate: $100 \mathrm{~mL} / \mathrm{min}$ ) and dry air (flow rate: $200 \mathrm{~mL} / \mathrm{min}$ ) at the anode and the cathode, respectively.

\section{Results and Discussion}

\subsection{Structure analysis}

Prior to fuel cell testing, fundamental analyses of the synthesized catalysts were performed using XPS, TGA, TEM and CV measurements. Fig. 1a shows the XPS narrow scans of the 9 different fabricated catalysts, in which we observed the $\mathrm{N}_{1 \mathrm{~s}}$ peak at $400 \mathrm{eV}$, which was derived from the nitrogen on PyPBI. $[5,6]$ The two peaks that appeared at 71.1 and $74.4 \mathrm{eV}$ are attributed to $\mathrm{Pt}_{4 \mathrm{f} 7 / 2}$ and $\mathrm{Pt}_{4 \mathrm{f5} / 2}$ (Fig. 1b), respectively, indicating successful deposition of $\mathrm{Pt}$ on the polymer-wrapped carbon supporting materials [37] (for the survey scans of these catalysts, see Supplementary Information, Fig. S1). The loading ratios of $\mathrm{Pt}$ on the PyPBI/ ${ }_{x} M W N T s-{ }_{y} C B$ as well as the PyPBI/CB and PyPBI/MWNTs were determined from the results of the TGA curves shown in Fig. 1c. The Pt loading ratios on the different catalysts were in the range of $50 \pm 2 \%$ as shown in Table 1.

The TEM images of the 9 catalysts are shown in Fig. 2, in which the dark spots are derived from the Pt-NPs. The TEM images show a good distribution of the Pt-NPs on the surfaces of 
the carbon supporting materials, which agreed with our previous results. [5, 6, 33, 34, 38, 39]

The insets in Fig. 2 display the Pt-NP diameter histograms obtained by calculating the particle size of $100 \mathrm{Pt}$ particles, and the determined Pt-NP sizes were approximately $4 \mathrm{~nm}$ as summarized in Table 1.

\subsection{Electrochemical measurements}

Fig. 3a shows the CV measurements of the 9 prepared electrocatalysts from which the characteristic peaks of the hydrogen adsorption/desorption and the Pt oxidation/reduction were observed. The ECSA values were calculated from the hydrogen adsorption peak in the CVs using eq. 1

$\mathrm{ECSA}=\mathrm{Q}_{\mathrm{H}} /\left(210 \times \mathrm{Pt}_{\text {loading on electrode }}\right)$

where $\mathrm{Q}_{\mathrm{H}}$ is the charges exchanged during the electroadsorption of $\mathrm{H}_{2}$ on Pt. The obtained ECSA values of the 9 catalysts were $\sim 48 \sim 53 \mathrm{~m}^{2} / \mathrm{g}_{\mathrm{Pt}}$ as summarized in Table 1 . Fig. $3 \mathrm{~b}$ shows the relation between the feeding ratios of the MWNTs and the ECSA values. The ECSA values increased with an increase in the MWNTs feeding ratios up to $10 \%$. The MWNTs are expected to work as filler between the stacked CB aggregates, leading to an improvement of the utilization efficiency of the deposited Pt-NPs as shown in Fig. 4. However, a further increase (over $30 \mathrm{wt} \%$ ) of the MWNTs feeding ratios led to a decrease in the ECSA values, probably due to a decrease in the active surface areas of the carbon supports because the MWNTs have lower surface areas compared to that of CB. [40] Another possible explanation 
is based on the result that the $\mathrm{PyPBI} / \mathrm{CB} / \mathrm{Pt}$ has smaller Pt-NPs than that of the PyPBI/MWNTs/Pt obtained from the XRD measurements (see Supplementary Information, Fig. S2 and Table S1), and smaller Pt-NPs $(\sim 2 \mathrm{~nm})$ on the CB have larger fractions of surface area in contact with the carbon support. [41] Thus, the addition of the MWNTs (up to 10\%) increased the Pt-NP size and reduced the attached surface area with the carbon support. However, further increase in the MWNTs feeding provided larger-sized Pt-NPs and decreased the ECSA. Based on the ECSA results, the PyPBI/10\%MWNTs- $90 \% \mathrm{CB} / \mathrm{Pt}$ composite was selected for the ORR measurement.

Fig. 5a shows the ORR polarization curves of the PyPBI $/ 10 \% \mathrm{MWNTs}-90 \% \mathrm{CB} / \mathrm{Pt}$, PyPBI/MWNT/Pt and PyPBI/CB/Pt. As observed, the half-wave potentials $\left(E_{1 / 2}\right)$ determined from the polarization curves were $786 \mathrm{mV}, 774 \mathrm{mV}, 767 \mathrm{mV}$ and $762 \mathrm{mV}$ for the PyPBI/10\%MWNTs- $90 \% \mathrm{CB} / \mathrm{Pt}$, PyPBI/MWNTs/Pt, PyPBI/CB/Pt and CB/Pt, respectively. [42] Meanwhile, the mixed kinetic-diffusion control region of the PyPBI $/ 10 \% \mathrm{MWNTs}-90 \% \mathrm{CB} / \mathrm{Pt}$ (between 0.8 and $0.9 \mathrm{~V} v$ s. RHE, inset) was positively shifted compared to those of the PyPBI/MWNTs/Pt, PyPBI/CB/Pt and CB/Pt. For a better understanding of the ORR activity, the kinetic current was calculated using the Levich-Koutecky equation: $1 / i=1 / i_{k}+1 / i_{d}$, where $i_{k}$ is the kinetic current and $i_{d}$ is the diffusion-limiting current. The obtained $i_{k}$ values at $0.85 \mathrm{~V}$ vs. RHE were used to calculate the Pt mass activity by normalizing the Pt loading. As shown in Fig. 5b, the mass activity of the PyPBI/10\%MWNTs- $-90 \% \mathrm{CB} / \mathrm{Pt}\left(120 \mathrm{~mA} / \mathrm{mg}_{\mathrm{Pt}}\right)$ was 1.5 and 2 
times higher than those of the PyPBI/MWNTs/Pt $\left(81 \mathrm{~mA} / \mathrm{mg}_{\mathrm{Pt}}\right)$ and PyPBI/CB/Pt (72 $\left.\mathrm{mA} / \mathrm{mg}_{\mathrm{Pt}}\right)$ at $0.85 \mathrm{~V}$ vs. RHE. The specific activity of the PyPBI $/ 10 \% \mathrm{MWNTs}-90 \% \mathrm{CB} / \mathrm{Pt}$ was determined to be $0.211 \mathrm{~mA} / \mathrm{cm}^{2}{ }_{\mathrm{Pt}}$ at $0.85 \mathrm{~V}$ vs. RHE, which was $\sim 1.3$ and 1.7 times higher than those of the PyPBI/MWNTs/Pt $\left(0.168 \mathrm{~mA} / \mathrm{cm}^{2}{ }_{\mathrm{Pt}}\right)$ and $\mathrm{PyPBI} / \mathrm{CB} / \mathrm{Pt}\left(0.125 \mathrm{~mA} / \mathrm{cm}^{2}{ }_{\mathrm{Pt}}\right)$. The observed enhanced catalytic activity of the PyPBI/ $10 \% \mathrm{MWNTs}-90 \% \mathrm{CB} / \mathrm{Pt}$ would be due to a synergetic effect derived from the hybrid nanostructure formed by the MWNTs and CB; namely, the addition of the MWNTs, that have a cylindrical structure, [43] to CB would form a 3D network structure that would enhance the oxygen diffusion and adsorption on the active sites, $[25,44]$ Also, the electronic conductivity of the hybrid materials was enhanced due to much higher conductivity of the MWNTs $(5.15 \mathrm{~S} / \mathrm{cm})$ compared to that of $\mathrm{CB}(0.58 \mathrm{~S} / \mathrm{cm})$. [45] Compared to the PyPBI/MWNTs/Pt, the Pt-NPs utilization of the $\mathrm{PyPBI} /{ }_{10 \% \mathrm{MWNTs}}-90 \% \mathrm{CB} / \mathrm{Pt}$ was also higher. Thus, the PyPBI/10\%MWNTs- $90 \% \mathrm{CB} / \mathrm{Pt}$ showed such a high ORR activity. Furthermore, the mass and specific activities of the

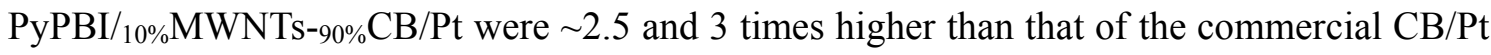
which were $51 \mathrm{~mA} / \mathrm{mg}_{\mathrm{Pt}}$ and $0.07 \mathrm{~mA} / \mathrm{cm}^{2}{ }_{\mathrm{Pt}}$ agreed with the previous reports. [46, 47]

\subsection{Durability test results}

The durability of the electrocatalysts was monitored by continued CV cycling from -0.17 to

$0.93 \mathrm{~V}$ vs. $\mathrm{Ag} / \mathrm{AgCl}$. [48] Fig. 5c shows the normalized ECSAs of the electrocatalysts during the durability testing, from which we recognize that the durability of the 
$\mathrm{PyPBI} /{ }_{10 \% \mathrm{MWNTs}}-90 \% \mathrm{CB} / \mathrm{Pt}$ (43\% loss) was almost the same as that of the PyPBI/MWNTs/Pt (48\% loss) and much higher than that of the PyPBI/CB/Pt (80\% loss) and $\mathrm{CB} / \mathrm{Pt}(88 \%)$. Meanwhile, the PyPBI/10\%MWNTs- $90 \% \mathrm{CB} / \mathrm{Pt}$ was more durable than the other electrocatalysts measured under the same conditions (see Supplementary Information, Table S2). The better durability was due to our unique electrocatalyst fabrication, in which the Pt-NPs bond to the PyPBI via Pt-N bonding, which prevented the Pt-NPs migration and aggregation. [33] The durability testing results of the other 6 catalysts are shown in Fig. S3. All the prepared MWNT-CB hybrid catalysts showed an enhanced durability compared to that of the CB based catalyst. For more details about the durability, the morphologies of the catalysts after the CV cycling were examined by TEM observation. As shown in Fig. 6 and its histograms (insets), the diameters of the Pt-NPs grown after the durability testing are consistent with the observed decrease in the ECSA values. [48] Interestingly, the PyPBI/10\% $\mathrm{MWNTs}-90 \% \mathrm{CB} / \mathrm{Pt}$ showed the lowest Pt growth and the lowest particle size distribution $(6.74 \pm 2.57 \mathrm{~nm})$ compared to those of the PyPBI/MWNTs/Pt $(7.49 \pm 5.68 \mathrm{~nm}), \mathrm{PyPBI} / \mathrm{CB} / \mathrm{Pt}(8.14 \pm 5.20 \mathrm{~nm})$ and $\mathrm{CB} / \mathrm{Pt}$ $(8.99 \pm 6.45 \mathrm{~nm}$, see Supplementary Information, Fig. S4), indicating the enhanced durability on the PyPBI/ $10 \% \mathrm{MWNTs}-90 \% \mathrm{CB} / \mathrm{Pt}$ because the stacked $\mathrm{CB}$ spherical structures allowed the Pt-NPs to be close to each other leading to agglomeration. [23] However, the addition of the MWNTs would isolate such stacked CB structures and prevent the agglomeration of Pt-NPs.

\subsection{Fuel cell test results}


In order to study the effect of the hybrid structure on the FC performance, the PyPBI $/ 10 \% \mathrm{MWNTs}-90 \% \mathrm{CB} / \mathrm{Pt}$, PyPBI/MWNTs/Pt and PyPBI/CB/Pt were used to fabricate the MEAs with a Pt loading of $0.45 \mathrm{mg}_{\mathrm{Pt}} / \mathrm{cm}^{2}$ each on both the cathode and anode sides. The FC performance of the assembled MEAs was measured at $120^{\circ} \mathrm{C}$ without adding any external humidification (namely, no humidified condition). Fig. 7 shows the potential and power density curves of the assembled MEAs. The maximum power densities of the MEAs using the

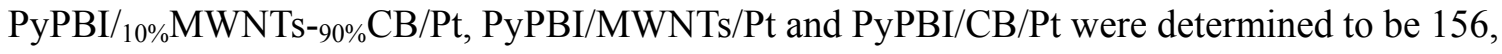
160 and $120 \mathrm{~mW} / \mathrm{cm}^{2}$, respectively. As observed, the feeding of $10 \%$-MWNTs to the CB catalyst layer improved the power density by $\sim 30 \%$, which was derived from the enhanced oxygen accessibility, ORR activity and the electron transfer from/to the active sites into the catalyst layers. The $\mathrm{PyPBI} / 10 \% \mathrm{MWNTs}-90 \% \mathrm{CB} / \mathrm{Pt}$ showed an almost 2 times higher power density than that of the $\mathrm{CB} / \mathrm{Pt}\left(88 \mathrm{~mW} / \mathrm{cm}^{2}\right)$ due to the higher ORR activity. The prepared

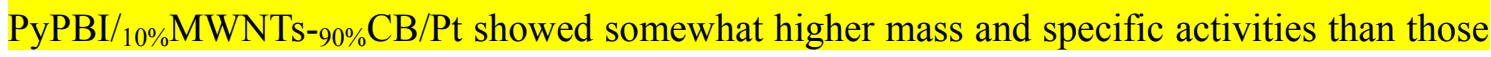
of the PyPBI/MWNTs/Pt; however, the power density of the hybrid catalyst was almost similar to that of the PyPBI/MWNTs/Pt, which would be due to the fact that the gas diffusion also affects the power density of PEMFC. Compared to the MWNT-based MEA, in which the MWNTs have a porous structure that enables smooth gas diffusion during the fuel cell operation, [49] the MWNT/CB hybrids on the MWNT/CB-based MEA has less porous structures since the $\mathrm{CB}$ forms a dense structure. We like to emphasize that the present study is 
important to prepare a less expensive fuel cell electrocatalyst because, based on our unique polymer wrapping method, $\sim 90 \mathrm{wt} \%$ of the MWNTs can be replaced with low cost CB while retaining a similar durability and power density in high temperature PEMFC.

\section{Conclusion}

Nine different fuel cell electrocatalysts were synthesized using polymer wrapped-MWNTs and $\mathrm{CB}$ by changing the feeding ratios of the MWNTs to $\mathrm{CB}$. The catalyst mass activity after feeding only $10 \%$-MWNTs to $\mathrm{CB}$ increased $\sim 1.5$ and 2 times higher than that of the MWNTs-based catalyst and CB-based catalyst, respectively, and such a catalyst showed a high durability comparable to the $100 \%$-MWNT-based catalyst. The obtained results demonstrated that $90-\mathrm{wt} \%$ of the MWNTs in the catalyst is able to be replaced by CB without any significant change in durability and power density. The remarkable mechanical and electrical properties of the MWNTs have made the feeding of the reactant and the transfer of electrons to/from the active sites in the CB catalyst layer much easily. The present results are important in order to develop an inexpensive fuel cell electrocatalyst with a high performance for next-generation PEMFCs. Further enhancement of FC performance is still under way in our lab.

\section{Acknowledgement}

This work was supported in part by the Low-Carbon Research Network (LCnet) and the Nanotechnology Platform Project (Molecules and Materials Synthesis) of the Ministry of 
Education, Culture, Sports, Science and Technology (MEXT), Japan and by The Japan Science and Technology Agency (JST) through its Center of Innovation Science and Technology-based Radical Innovation and Entrepreneurship Program (COI Program). Z. H. Yang acknowledges to China Scholarship Council (CSC) for their support.

\section{References}

[1] T. Fujigaya, N. Nakashima, Fuel cell electrocatalyst using polybenzimidazole-modified carbon nanotubes as support materials, Adv. Mater., 25 (2013) 1666-1681.

[2] H.W. Liang, X. Cao, F. Zhou, C.H. Cui, W.J. Zhang, S.H. Yu, A free-standing Pt-nanowire membrane as a highly stable electrocatalyst for the oxygen reduction reaction, Adv. Mater., 23 (2011) 1467-1471.

[3] G. Wu, K.L. More, C.M. Johnston, P. Zelenay, High-performance electrocatalysts for oxygen reduction derived from polyaniline, iron, and cobalt, Science, 332 (2011) 443-447.

[4] W. Phompan, N. Hansupalak, Improvement of proton-exchange membrane fuel cell performance using platinum-loaded carbon black entrapped in crosslinked chitosan, J. Power Sources, 196 (2011) 147-152.

[5] M.R. Berber, T. Fujigaya, K. Sasaki, N. Nakashima, Remarkably Durable High Temperature Polymer Electrolyte Fuel Cell Based on Poly(vinylphosphonic acid)-doped Polybenzimidazole, Sci. Rep., 3 (2013).

[6] M.R. Berber, T. Fujigaya, N. Nakashima, High-temperature polymer electrolyte fuel cell using poly(vinylphosphonic acid) as an electrolyte shows a remarkable durability, ChemCatChem, 6 (2014) 567-571.

[7] R. Choi, S.-I. Choi, C.H. Choi, K.M. Nam, S.I. Woo, J.T. Park, S.W. Han, Designed Synthesis of Well-Defined Pd@Pt Core-Shell Nanoparticles with Controlled Shell Thickness as Efficient Oxygen Reduction Electrocatalysts, Chem. Eur. J., 19 (2013) 8190-8198.

[8] F. Pereira, A. Chan, K. Vallé, P. Palmas, J. Bigarré, P. Belleville, C. Sanchez, Design of Interpenetrated Networks of Mesostructured Hybrid Silica and Nonconductive Poly(vinylidene fluoride)-Cohexafluoropropylene (PVdF-HFP) Polymer for Proton Exchange Membrane Fuel Cell Applications, Chem. Asian. J., 6 (2011) 1217-1224.

[9] X. Cui, Z. Hua, C. Wei, Z. Shu, L. Zhang, H. Chen, J. Shi, An In Situ CarbonizationReplication Method to Synthesize Mesostructured WO3/C Composite as Nonprecious-Metal Anode Catalyst in PEMFC, Chem. Asian. J., 8 (2013) 429-436.

[10] A.Z. Weber, A. Kusoglu, Unexplained transport resistances for low-loaded fuel-cell catalyst layers, J. Mater. Chem. A, 2 (2014) 17207-17211.

[11] G.S. Tasic, S.S. Miljanic, M.P. Marceta Kaninski, D.P. Saponjic, V.M. Nikolic, 
Non-noble metal catalyst for a future Pt free PEMFC, Electrochem. Commun., 11 (2009) 2097-2100.

[12] Y. Shao, G. Yin, Y. Gao, Understanding and approaches for the durability issues of Pt-based catalysts for PEM fuel cell, J. Power Sources, 171 (2007) 558-566.

[13] F.J. Nores-Pondal, I.M.J. Vilella, H. Troiani, M. Granada, S.R. de Miguel, O.A. Scelza, H.R. Corti, Catalytic activity vs. size correlation in platinum catalysts of PEM fuel cells prepared on carbon black by different methods, Int. J. Hydrogen Energy, 34 (2009) 8193-8203.

[14] X. Zhou, Y. Gan, J. Du, D. Tian, R. Zhang, C. Yang, Z. Dai, A review of hollow Pt-based nanocatalysts applied in proton exchange membrane fuel cells, J. Power Sources, 232 (2013) 310-322.

[15] R.L. Borup, J.R. Davey, F.H. Garzon, D.L. Wood, M.A. Inbody, PEM fuel cell electrocatalyst durability measurements, J. Power Sources, 163 (2006) 76-81.

[16] A. Chen, P. Holt-Hindle, Platinum-based nanostructured materials: Synthesis, properties, and applications, Chem. Rev., 110 (2010) 3767-3804.

[17] H. Jiang, Y. Zhu, Q. Feng, Y. Su, X. Yang, C. Li, Nitrogen and Phosphorus Dual-Doped Hierarchical Porous Carbon Foams as Efficient Metal-Free Electrocatalysts for Oxygen Reduction Reactions, Chem. Eur. J., 20 (2014) 3106-3112.

[18] Z. Yang, I.H. Hafez, M.R. Berber, N. Nakashima, An Enhanced Anode based on Polymer-Coated Carbon Black for use as a Direct Methanol Fuel Cell Electrocatalyst, ChemCatChem, 7 (2015) 808-813.

[19] Z. Yang, M.R. Berber, N. Nakashima, A polymer-coated carbon black-based fuel cell electrocatalyst with high CO-tolerance and durability in direct methanol oxidation, J. Mater. Chem. A, 2 (2014) 18875-18880.

[20] D. Banham, F. Feng, K. Pei, S. Ye, V. Birss, Effect of carbon support nanostructure on the oxygen reduction activity of Pt/C catalysts, J. Mater. Chem. A, 1 (2013) 2812-2820.

[21] S. Maass, F. Finsterwalder, G. Frank, R. Hartmann, C. Merten, Carbon support oxidation in PEM fuel cell cathodes, J. Power Sources, 176 (2008) 444-451.

[22] X. Zhao, A. Hayashi, Z. Noda, K. Kimijima, I. Yagi, K. Sasaki, Evaluation of change in nanostructure through the heat treatment of carbon materials and their durability for the start/stop operation of polymer electrolyte fuel cells, Electrochim. Acta, 97 (2013) 33-41.

[23] M. Hara, M. Lee, C.H. Liu, B.H. Chen, Y. Yamashita, M. Uchida, H. Uchida, M. Watanabe, Electrochemical and Raman spectroscopic evaluation of Pt/graphitized carbon black catalyst durability for the start/stop operating condition of polymer electrolyte fuel cells, Electrochim. Acta, 70 (2012) 171-181.

[24] H. Gharibi, M. Javaheri, R.A. Mirzaie, The synergy between multi-wall carbon nanotubes and Vulcan XC72R in microporous layers, Int. J. Hydrogen Energy, 35 (2010) 9241-9251.

[25] H.-T. Kim, J.-K. Lee, J. Kim, Platinum-sputtered electrode based on blend of carbon 
nanotubes and carbon black for polymer electrolyte fuel cell, J. Power Sources, 180 (2008) 191-194.

[26] Z. Tang, C.K. Poh, K.K. Lee, Z. Tian, D.H.C. Chua, J. Lin, Enhanced catalytic properties from platinum nanodots covered carbon nanotubes for proton-exchange membrane fuel cells, J. Power Sources, 195 (2010) 155-159.

[27] M.M. Shaijumon, S. Ramaprabhu, N. Rajalakshmi, Platinum/multiwalled carbon nanotubes-platinum/carbon composites as electrocatalysts for oxygen reduction reaction in proton exchange membrane fuel cell, Appl. Phys. Lett., 88 (2006).

[28] H. Nakano, W. Li, L. Xu, Z. Chen, M. Waje, S. Kuwabata, Y. Yan, Carbon nanotube and carbon black supported platinum nanocomposites as oxygen reduction electrocatalysts for polymer electrolyte fuel cells, Electrochemistry, 75 (2007) 705-708.

[29] Y. Oono, A. Sounai, M. Hori, Influence of the phosphoric acid-doping level in a polybenzimidazole membrane on the cell performance of high-temperature proton exchange membrane fuel cells, J. Power Sources, 189 (2009) 943-949.

[30] Q. Li, J.O. Jensen, R.F. Savinell, N.J. Bjerrum, High temperature proton exchange membranes based on polybenzimidazoles for fuel cells, Prog. Polym. Sci., 34 (2009) 449-477. [31] K. Matsumoto, T. Fujigaya, H. Yanagi, N. Nakashima, Very High Performance Alkali Anion-Exchange Membrane Fuel Cells, Adv. Funct. Mater., 21 (2011) 1089-1094.

[32] K. Matsumoto, T. Fujigaya, K. Sasaki, N. Nakashima, Bottom-up design of carbon nanotube-based electrocatalysts and their application in high temperature operating polymer electrolyte fuel cells, J. Mater. Chem., 21 (2011) 1187-1190.

[33] T. Fujigaya, M. Okamoto, N. Nakashima, Design of an assembly of pyridine-containing polybenzimidazole, carbon nanotubes and Pt nanoparticles for a fuel cell electrocatalyst with a high electrochemically active surface area, Carbon, 47 (2009) 3227-3232.

[34] M. Okamoto, T. Fujigaya, N. Nakashima, Design of an assembly of poly(benzimidazole), carbon nanotubes, and Pt nanoparticles for a fuel-cell electrocatalyst with an ideal interfacial nanostructure, Small, 5 (2009) 735-740.

[35] T. Brock, D.C. Sherrington, H.G. Tang, Synthesis and characterization of polybenzimidazoles carrying additional pyridine and imidazole groups in the main chain, Polymer, 32 (1991) 353-357.

[36] L. Xiao, H. Zhang, T. Jana, E. Scanlon, R. Chen, E.W. Choe, L.S. Ramanathan, S. Yu, B.C. Benicewicz, Synthesis and characterization of pyridine-based polybenzimidazoles for high temperature polymer electrolyte membrane fuel cell applicationsx, Fuel Cells, 5 (2005) 287-295.

[37] B. Fang, N.K. Chaudhari, M.S. Kim, H.K. Jung, J.S. Yu, Homogeneous deposition of platinum nanoparticles on carbon black for proton exchange membrane fuel cell, J. Am. Chem. Soc., 131 (2009) 15330-15338.

[38] M. Okamoto, T. Fujigaya, N. Nakashima, Individual Dissolution of Single-Walled Carbon Nanotubes by Using Polybenzimidazole, and Highly Effective Reinforcement of 
Their Composite Films, Adv. Funct. Mater., 18 (2008) 1776-1782.

[39] T. Fujigaya, M. Okamoto, K. Matsumoto, K. Kaneko, N. Nakashima, Interfacial engineering of platinum catalysts for fuel cells: Methanol oxidation is dramatically improved by polymer coating on a platinum catalyst, ChemCatChem, 5 (2013) 1701-1704.

[40] C. Paoletti, A. Cemmi, L. Giorgi, R. Giorgi, L. Pilloni, E. Serra, M. Pasquali, Electro-deposition on carbon black and carbon nanotubes of $\mathrm{Pt}$ nanostructured catalysts for methanol oxidation, J. Power Sources, 183 (2008) 84-91.

[41] K. Yu, D.J. Groom, X. Wang, Z. Yang, M. Gummalla, S.C. Ball, D.J. Myers, P.J. Ferreira, Degradation Mechanisms of Platinum Nanoparticle Catalysts in Proton Exchange Membrane Fuel Cells: The Role of Particle Size, Chem. Mater., 26 (2014) 5540-5548.

[42] Y. Li, W. Zhou, H. Wang, L. Xie, Y. Liang, F. Wei, J.C. Idrobo, S.J. Pennycook, H. Dai, An oxygen reduction electrocatalyst based on carbon nanotube-graphene complexes, Nat. Nanotechnol., 7 (2012) 394-400.

[43] A. Srivastava, O.N. Srivastava, S. Talapatra, R. Vajtai, P.M. Ajayan, Carbon nanotube filters, Nat. Mater., 3 (2004) 610-614.

[44] K.-S. Kim, S.-J. Park, High electrochemical performance of carbon black-bonded carbon nanotubes for electrode materials, Mater. Res. Bull., 47 (2012) 4146-4150.

[45] P.C. Ma, M.Y. Liu, H. Zhang, S.Q. Wang, R. Wang, K. Wang, Y.K. Wong, B.Z. Tang, S.H. Hong, K.W. Paik, J.K. Kim, Enhanced electrical conductivity of nanocomposites containing hybrid fillers of carbon nanotubes and carbon black, ACS Appl. Mater. Interfaces, 1 (2009) 1090-1096.

[46] S. Beak, D. Jung, K.S. Nahm, P. Kim, Preparation of highly dispersed Pt on TiO2-modified carbon for the application to oxygen reduction reaction, Catal. Lett., 134 (2010) 288-294.

[47] J.-H. Jang, J. Kim, Y.-H. Lee, I.Y. Kim, M.-H. Park, C.-W. Yang, S.-J. Hwang, Y.-U. Kwon, One-pot synthesis of core-shell-like Pt3Co nanoparticle electrocatalyst with Pt-enriched surface for oxygen reduction reaction in fuel cells, Energy Environ. Sci., 4 (2011) 4947-4953.

[48] S. Chen, Z. Wei, X. Qi, L. Dong, Y.G. Guo, L. Wan, Z. Shao, L. Li, Nanostructured polyaniline-decorated Pt/C@PANI core-shell catalyst with enhanced durability and activity, J. Am. Chem. Soc., 134 (2012) 13252-13255.

[49] M.R. Berber, I.H. Hafez, T. Fujigaya, N. Nakashima, Durability analysis of polymer-coated pristine carbon nanotube-based fuel cell electrocatalysts under non-humidified conditions, J. Mater. Chem. A, 2 (2014) 19053-19059.

Table 1 Comparison of Pt contents, particle diameters and ECSA values for different electrocatalysts. 


\begin{tabular}{cccc}
\hline Sample & Pt content $(\mathrm{wt} \%)$ & $\begin{array}{c}\text { Size of Pt-NPs } \\
(\mathrm{nm})\end{array}$ & $\begin{array}{c}\text { ECSA } \\
\left(\mathrm{m}^{2} / \mathrm{g}_{\mathrm{Pt}}\right)\end{array}$ \\
\hline PyPBI/CB/Pt & 50.41 & $4.12 \pm 0.6$ & 50.8 \\
$\mathrm{PyPBI} /{ }_{2 \% \mathrm{MWNTs}-98 \% \mathrm{CB} / \mathrm{Pt}}$ & 49.26 & $3.78 \pm 0.4$ & 51.2 \\
$\mathrm{PyPBI} /{ }_{5 \%} \mathrm{MWNTs}-95 \% \mathrm{CB} / \mathrm{Pt}$ & 50.50 & $4.37 \pm 0.5$ & 51.5 \\
$\mathrm{PyPBI} /{ }_{10 \% \mathrm{MWNTs}-90 \% \mathrm{CB} / \mathrm{Pt}}$ & 49.70 & $4.06 \pm 0.5$ & 53.2 \\
$\mathrm{PyPBI} /{ }_{30 \% \mathrm{MWNTs}-70 \% \mathrm{CB} / \mathrm{Pt}}$ & 49.68 & $4.53 \pm 0.5$ & 49.1 \\
$\mathrm{PyPBI} /{ }_{50 \% \mathrm{MWNTs}}{ }_{50 \%} \mathrm{CB} / \mathrm{Pt}$ & 52.10 & $4.18 \pm 0.5$ & 49.0 \\
$\mathrm{PyPBI} /{ }_{70 \% \mathrm{MWNTs}-30 \% \mathrm{CB} / \mathrm{Pt}}$ & 52.08 & $3.82 \pm 0.6$ & 48.7 \\
$\mathrm{PyPBI} /{ }_{90 \% \mathrm{MWNTs}-10 \% \mathrm{CB} / \mathrm{Pt}}$ & 51.79 & $3.77 \pm 0.5$ & 48.5 \\
PyPBI/MWNTs/Pt & 47.25 & $4.32 \pm 0.7$ & 48.2 \\
\hline
\end{tabular}
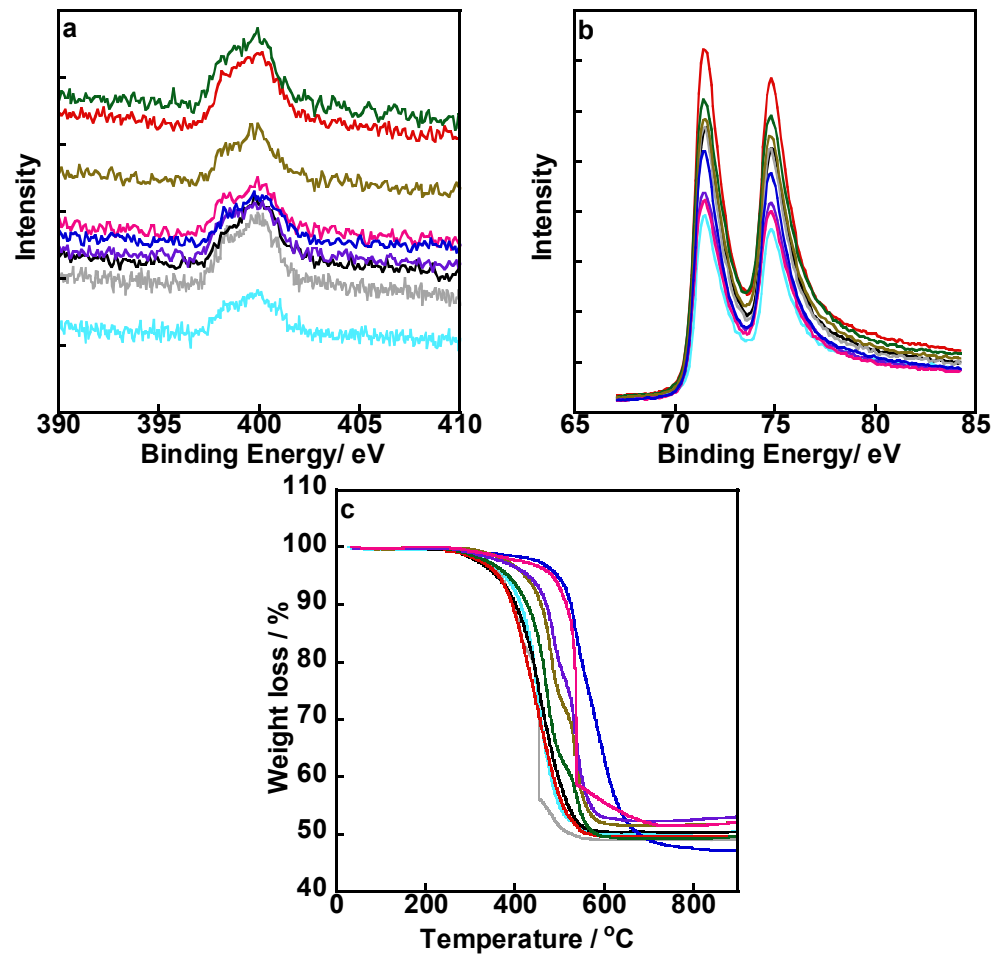

Fig. 1 XPS spectra of narrow scans of $\mathrm{N}_{1 \mathrm{~s}}$ (a) and $\mathrm{Pt}_{4 \mathrm{f}}$ (b) regions of the $\mathrm{PyPBI} /{ }_{\mathrm{x}} \mathrm{MWNTs}-\mathrm{CB} / \mathrm{Pt}$. TGA curves of 9 different catalysts are shown in (c). In the figure, the $x$ and $y$ values and their colors were black $(x / y=0 / 100)$, grey $(x / y=2 / 98)$, sky blue $(x / y=5 / 95)$, red $(x / y=10 / 90)$, green $(x / y=30 / 70)$, dark green $(x / y=50 / 50)$,purple $(x / y=70 / 30)$, pink $(\mathrm{x} / \mathrm{y}=90 / 10)$ and blue $(\mathrm{x} / \mathrm{y}=100 / 0)$. 


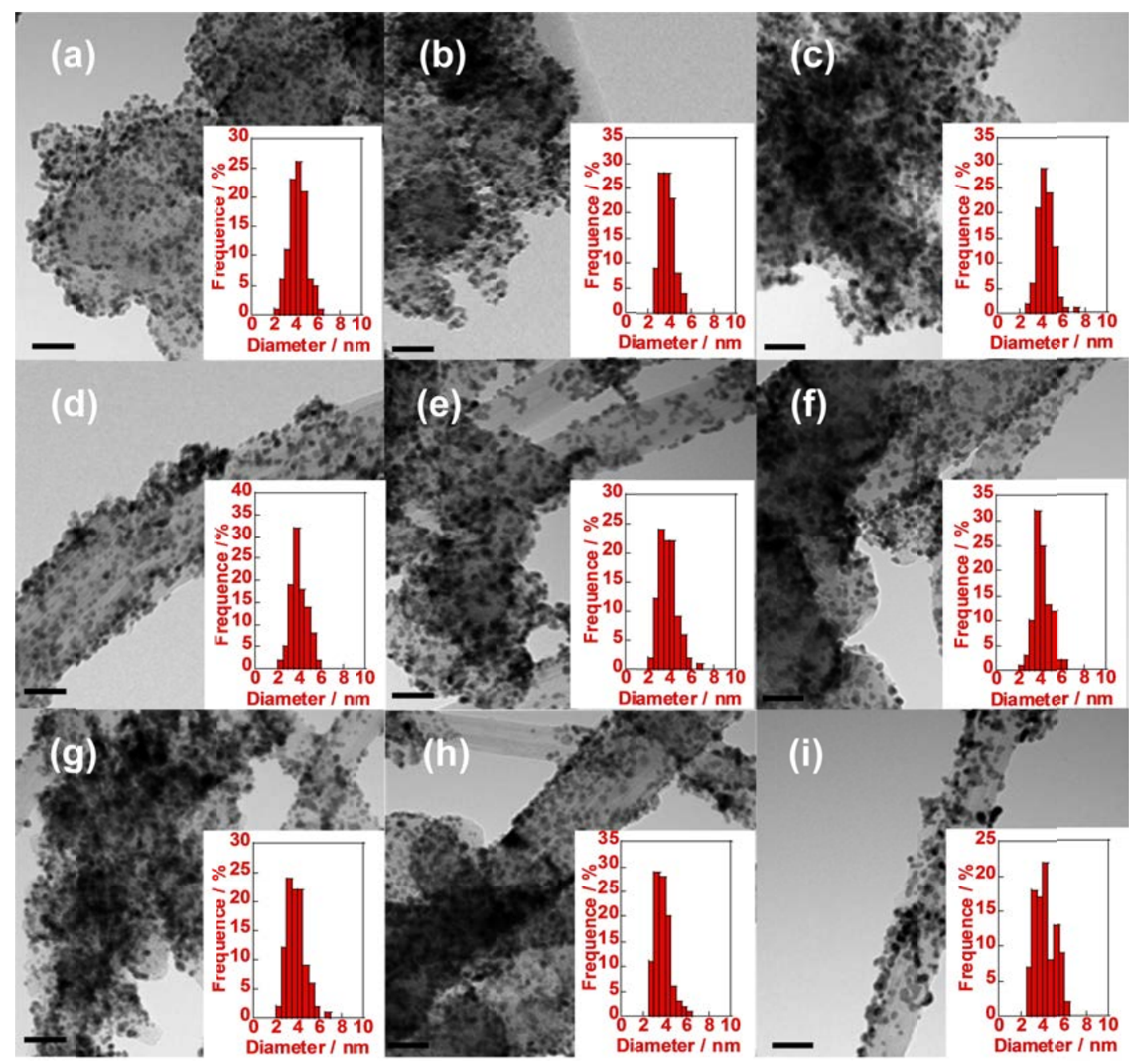

Fig. 2 TEM images of the PyPBI/CB/Pt (a), PyPBI $/ 2 \% \mathrm{MWNTs}-98 \% \mathrm{CB} / \mathrm{Pt}$ (b), $\mathrm{PyPBI} / 5 \% \mathrm{MWNTs}-95 \% \mathrm{CB} / \mathrm{Pt}$ (c), $\mathrm{PyPBI} / 10 \% \mathrm{MWNTs}-90 \% \mathrm{CB} / \mathrm{Pt}$ (d), $\mathrm{PyPBI} / 30 \% \mathrm{MWNTs}-70 \% \mathrm{CB} / \mathrm{Pt}$ (e), $\quad \mathrm{PyPBI} / 50 \% \mathrm{MWNTs}-50 \% \mathrm{CB} / \mathrm{Pt}$ PyPBI/70\%MWNTs- $30 \% \mathrm{CB} / \mathrm{Pt}$ (g), PyPBI/90\%MWNTs- $10 \% \mathrm{CB} / \mathrm{Pt}$ (h) and PyPBI/MWNTs/Pt (i) catalysts. Scale bars, $20 \mathrm{~nm}$. Diameter distribution histograms of Pt-NPs (taken from100 particles) are shown in the insets. 

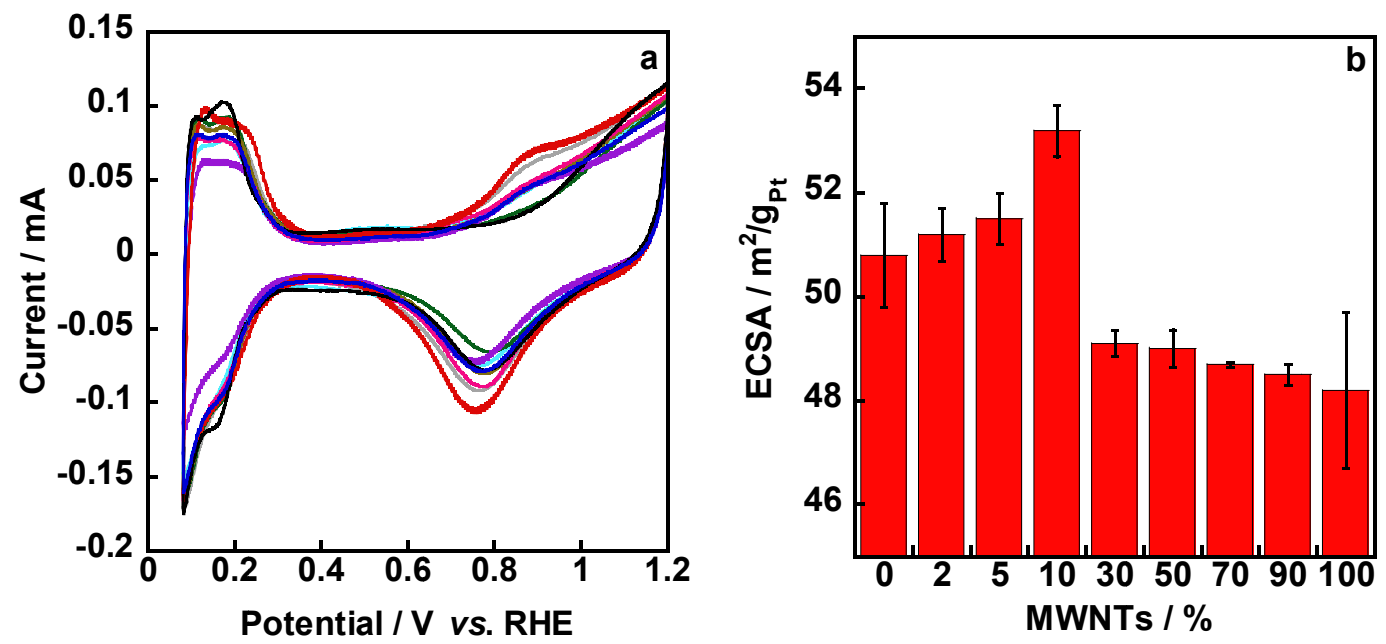

Fig. 3 (a) CV curves of the PyPBI/xMWNTs- ${ }_{y} \mathrm{CB} / \mathrm{Pt}$, in which their colors and the $\mathrm{x} / \mathrm{y}$ values are black $(x / y=0 / 100)$, grey $(x / y=2 / 98)$, sky blue $(x / y=5 / 95)$, red $(x / y=10 / 90)$, green $(\mathrm{x} / \mathrm{y}=30 / 70)$, dark green $(\mathrm{x} / \mathrm{y}=50 / 50)$, purple $(\mathrm{x} / \mathrm{y}=70 / 30)$, pink $(\mathrm{x} / \mathrm{y}=90 / 10)$, and blue $(\mathrm{x} / \mathrm{y}=100 / 0)$. (b) ECSA values of the 9 catalysts with specified MWNTs contents.

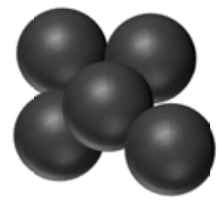

CB

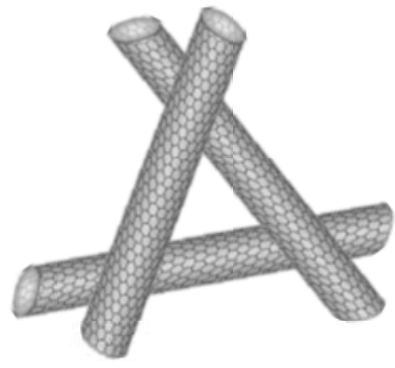

MWNTs

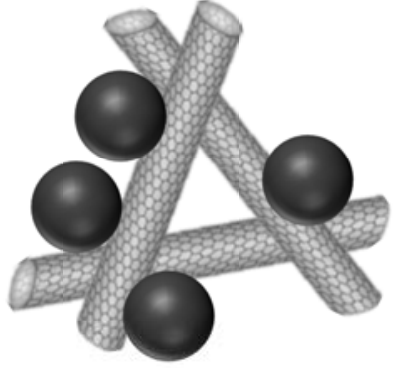

MWNTs/CB

Fig. 4 Schematic illuminations of the structures of CB, MWNTs, MWNTs/CB. 

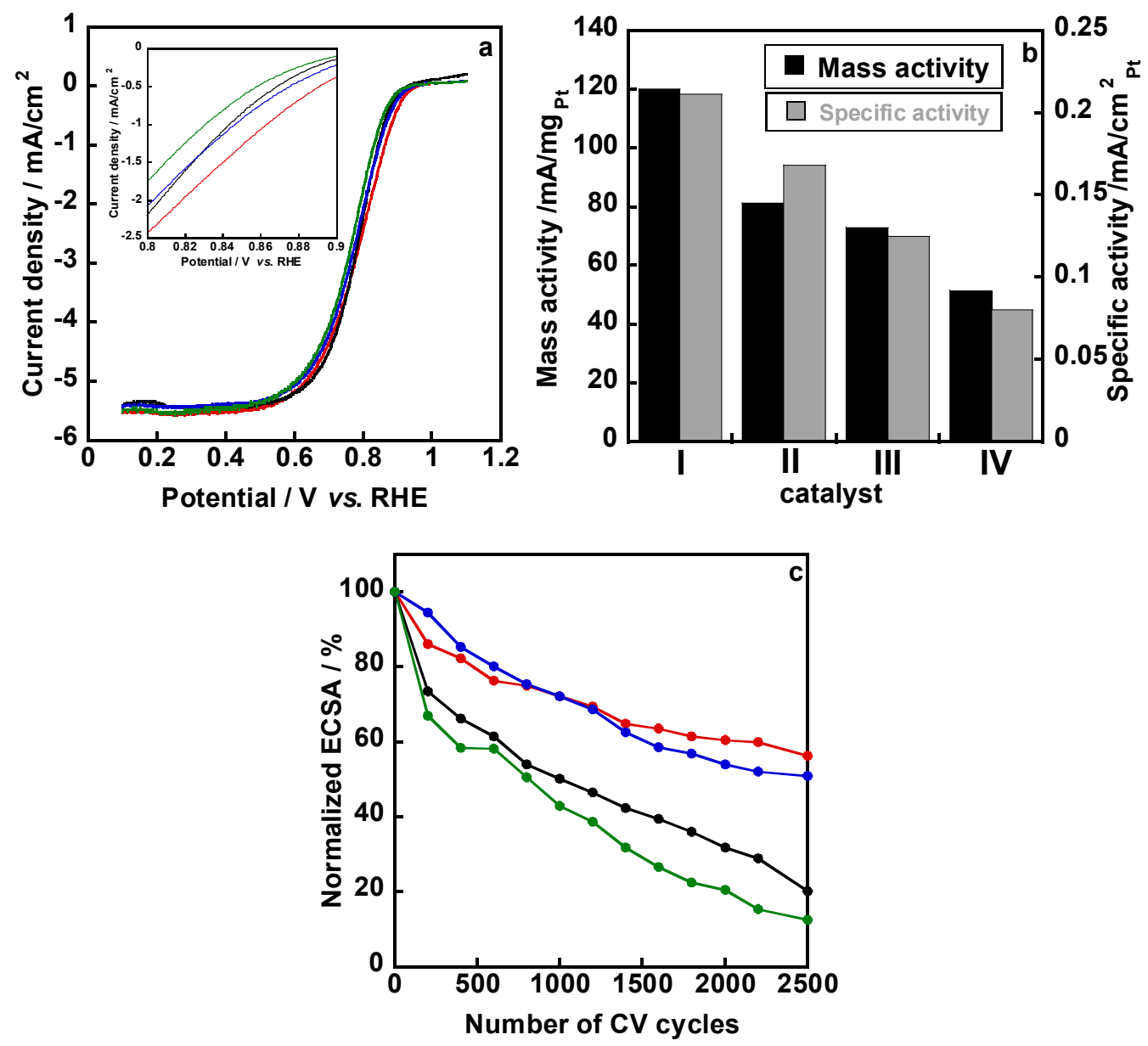

Fig. 5 (a) ORR polarization curves of the $\mathrm{PyPBI} / 10 \% \mathrm{MWNTs}-90 \% \mathrm{CB} / \mathrm{Pt}$ (red), PyPBI/MWNTs/Pt (blue), PyPBI/CB/Pt (black) and CB/Pt (green). (b) Mass and specific activities (@0.85 V vs. RHE) for the PyPBI/10\%MWNTs- $90 \% \mathrm{CB} / \mathrm{Pt}$ (I), PyPBI/MWNTs/Pt (II),PyPBI/CB/Pt (III) and $\mathrm{CB} / \mathrm{Pt}$ (IV). (c) Normalized ECSA values of the $\mathrm{PyPBI} / 10 \% \mathrm{MWNTs}-90 \% \mathrm{CB} / \mathrm{Pt}$ (red), PyPBI/MWNTs/Pt (blue), PyPBI/CB/Pt (black) and $\mathrm{CB} / \mathrm{Pt}$ (green) as a function of $\mathrm{CV}$ cycling measured in $\mathrm{N}_{2}$-saturated $0.1 \mathrm{M} \mathrm{HClO}_{4}$ solution at room temperature (0.1-1.2 V vs. RHE, $50 \mathrm{mV} / \mathrm{s}$ sweep rate). 

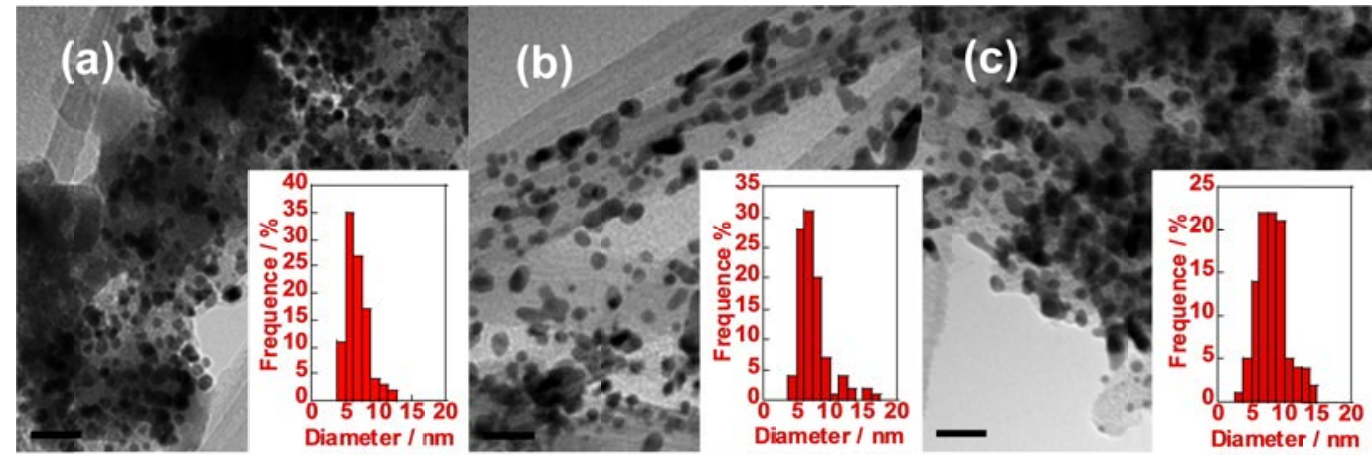

Fig. 6 TEM images of the PyPBI/10\%MWNTs- $-90 \% \mathrm{CB} / \mathrm{Pt}$ (a), PyPBI/MWNTs/Pt (b) and PyPBI/CB/Pt (c) after the durability test. Scale bars: $20 \mathrm{~nm}$. Diameter distribution histograms of Pt-NPs (taken from 100 particles) are shown in the insets.

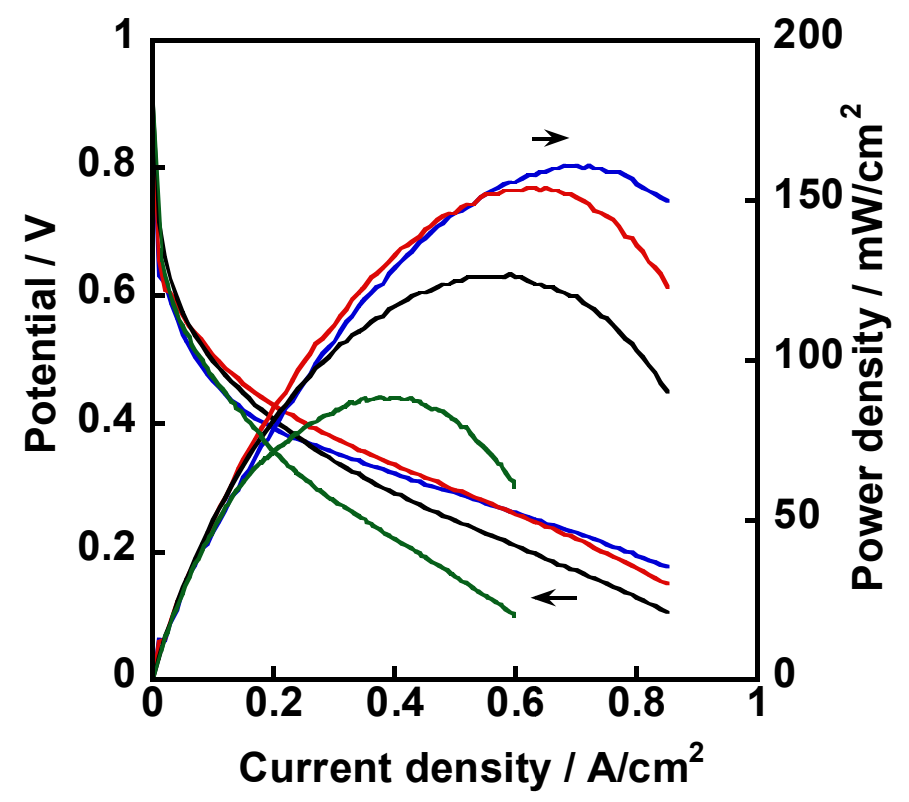

Fig. 7 Polarization of $\mathrm{I}-\mathrm{V}$ and power density curves of the MEAs fabricated using the $\mathrm{PyPBI} / 10 \% \mathrm{MWNTs}-90 \% \mathrm{CB} / \mathrm{Pt}$ (red), PyPBI/MWNTs/Pt (blue), PyPBI/CB/Pt (black) and CB/Pt (green) under non-humidified condition at $120^{\circ} \mathrm{C}$. 